\title{
Experience with Flaps After Resection of Vulvar Carcinoma: A Case Series
}

\author{
Jiaqi Zhang \\ Sun Yat-Sen Memorial Hospital \\ Jian Zhang \\ Sun Yat-Sen Memorial Hospital \\ Meng Liu \\ Sun Yat-Sen Memorial Hospital \\ Jun Ge \\ Sun Yat-Sen Memorial Hospital \\ Xiaolian Xiao \\ Sun Yat-Sen Memorial Hospital \\ Zheng Su \\ Sun Yat-Sen Memorial Hospital \\ Chen Chen \\ Sun Yat-Sen Memorial Hospital \\ Fen Shi \\ Sun Yat-Sen Memorial Hospital \\ Yongzhen Wang \\ Sun Yat-Sen Memorial Hospital \\ Weiqiang Liang ( $\square$ lweiq@mail.sysu.edu.cn) \\ Sun Yat-sen memorial hospital
}

\section{Research Article}

Keywords: Vulval tumor, Pedicled flap, Local flap, Vulvar reconstruction

Posted Date: December 1st, 2021

DOI: https://doi.org/10.21203/rs.3.rs-1069444/v1

License: (c) (i) This work is licensed under a Creative Commons Attribution 4.0 International License. Read Full License 


\section{Abstract}

Background: A defect caused by the radical resection of vulvar cancer requires repair with flap transplantation or vulvoplasty. Therefore, the aim of this study is to present a review of our practice of post-surgical defect reconstruction in cases using different skin flaps.

Methods: An observational study was performed among 26 patients with vulvar cancer who were admitted to Sun Yat-Sen Memorial Hospital between February 2015 and February 2020 for surgical and reconstructive procedures. Clinical data of these 26 patients were analyzed. All patients underwent radical resection of vulvar cancer, followed by the repair of post-surgical defects by random flap or axial flap transplantation (even for very complex defects).

Results: Among the 26 cases in this study, all patients received 38 soft tissue reconstruction procedures for vulvar perineal defects during the study period. Squamous cell carcinoma was the most commonly diagnosed cancer (80.8\%). The average size of the defect was $9.3^{\prime} 7 \mathrm{~cm} 2$. Rhomboid flaps were the most commonly used flaps for performing reconstruction in both the primary and recurrent groups. Poor wound healing was the most commonly discovered complication that occurred in 3 of the 38 flaps (7.9\%) used. Previous surgery or radiotherapy did not increase the rate of complications after proper reconstruction was performed.

Conclusion: Expanding resection is an effective technique for treating vulvar cancer. Different skin flaps, are effective premium options for post-surgical defect reconstruction, and selective use of skin flaps for treating vulvar defects preserves the vulvar morphology and allows for relatively better functionality.

\section{Background}

The cancer of the vulva is a rare type of cancer, which accounts for approximately $5 \%$ of all gynecological malignancies; squamous cell carcinomas make up $95 \%$ of all cancers [1]. Vulvar cancer has the following characteristics: strong invasion, rapid progression, and easy recurrence. The treatment method for vulvar cancer is extensive vulvar resection or inguinal lymphadenectomy, which often includes extensive resection of at least 2-3 cm around the cancer foci; this can effectively reduce the local recurrence rate [2]. However, extensive resection can lead to a large defect on the skin and soft tissue: the suture tension is very high, the wound can become easily infected after surgery, wound healing is difficult or delayed, scar hyperplasia leads to vaginal orifice stenosis, and sexual ability is reduced or lost after surgery; this affects the quality of life of patients (especially young patients). Reconstructive options include skin grafts, skin flaps, fasciocutaneous flaps, and myocutaneous flaps [3].

The primary objectives of reconstruction of vulvar defects are closure without any tension, less scarring of the perineum, and suturing of the donor area in a single stage. The secondary objectives of reconstruction of vulvar defects include sensitive reconstruction and preservation of sexual function [4-7], but these methods have some drawbacks. Defects of the groin, mons pubis, vagina, or urethra are frequently found during surgery for vulvar cancer, and single stage repair can cause deformity of the physiological structure in this area (which can affect the correct choice of the flap for reconstruction). Local and pedicled flaps are appropriate choices for most wounds; flap techniques can be technically demanding, but they are preferable in many cases because of minimal damage to the donor area, convenience in cutting, and minimal technical difficulty. Other very important considerations include possible previous radiotherapy and whether the inguinal lymph node has been cleaned. Thus, we aim to present a review of our experiences with flaps after resection of vulvar carcinoma, with critical analysis of surgical indications and flap selection based on the above-mentioned key points.

\section{Materials And Methods}

\section{Patients}

An observational study was performed among 26 patients with vulvar cancer who were admitted to Sun Yat-Sen Memorial Hospital between February 2015 and February 2020 for surgical and reconstructive procedures. Clinical data of these 26 patients were analyzed. The average age of all patients was 54.5 years, which ranged from 28 years to 73 years.

\section{Eligibility criteria for patient inclusion}

a- Inclusion criteria: (1) patients diagnosed with vulvar cancer;(2) patients undergoing primary surgery;(3) patients who developed recurrence; (4)patients with inguinal node metastasis.

b- Exclusion criteria:(1) The general condition is poor, combined with other serious systemic diseases; (2) Combined with other types of tumors; (3) Patients with mental diseases cannot cooperate to complete treatment and follow-up; $;$ (4) the follow-up data are lost and the patient and his family members cannot be contacted.

\section{Surgical techniques}

All patients underwent radical resection of vulvar cancer; this was followed by the repair of post-surgical defects by random flap or axial flap transplantation (even for very complex defects).

a- Radical resection of vulvar cancer 
The vulva, perineum, mons pubis, groins, vagina, and urethra were the most frequently included structures in resection, and the rectum, bladder, and lower abdominal wall were rarely included in resection. In 16 of these 26 cases, only extensive resection of the vulva was performed, and the remaining 10 cases were treated with extensive vulval resection + unilateral inguinal lymphadenectomy or bilateral inguinal lymphadenectomy.

b- Reconstruction of vulvar defects using flaps

Planned incisions for extirpative surgery were discussed preoperatively with the gynecologic oncologist to choose among the available reconstructive techniques. All 26 patients underwent simultaneous reconstruction of the vulva. During surgery, the size and shape of the flap were adjusted according to the specific location of the defect. The donor area of the flap was sutured directly. At the end of ablative surgery, the defect was re-evaluated in the operating room.

\section{Patient follow-up}

Patient follow-up was performed every 50.4 months after the surgical procedure. Regular nuclear magnetic resonance examination was conducted to monitor for local recurrence and lymph node metastasis. Further, positron emission tomography-computed tomography (PET-CT) examination was used to detect distant metastasis in patients with lymph node metastasis.

\section{Statistical analysis}

All data were analyzed with SPSS and descriptive statistical data are presented as the mean \pm SEM or percentage.

\section{Results}

Among 26 patients, tumor lesions had different sizes, and some of these lesions were associated with different degrees of vaginal mucosal or urethral orificial involvement. Of the 26 cases, there were 16 cases of primary surgery, 7 cases of recurrence, and 3 cases of simple inguinal

metastasis. Three cases had lesions in the pubic region, 8 cases had unilateral lesions, 10 cases had bilateral lesions, and 5 cases had perianal tissue invasion. Among 26 patients, 21 patients had squamous cell carcinoma, 3 patients had dermatofibrosarcoma protuberans, one patient had adenoid cystic carcinoma, and one patient had sebaceous gland carcinoma. Among 26 patients, two patients underwent cystostomy before surgery and 3 patients underwent colostomy before surgery (Table 2).

The skin defect size ranged from $4-26 \mathrm{~cm} \times 2.4-16 \mathrm{~cm}$, and the average defect size was $9.3 \times 7 \mathrm{~cm}$. Among 26 patients, 38 flaps were used for transplantation and the repair of defects. The area of the flap ranged from $4-30 \mathrm{~cm} \times 3-15 \mathrm{~cm}$. Of 26 cases, 13 cases were treated with rhomboid flaps, 4 cases were treated with traditional fasciocutaneous V-Y flaps, 6 cases were treated with medial femoral flaps, 1 case was treated with a vertical rectus abdominis musculocutaneous (VRAM) flap, and 2 cases were treated with combined flaps: 1 case was treated with combined VRAM flap and anterolateral thigh (ALT) flap, and the other case was treated with combined medial femoral flap and ALT flap (Table 1). Typical cases are shown in Figures 1-16.

The mean follow-up time ranged from 15 months to 50 months. Excluding the patient treated with a single flap that developed partial necrosis in the distal portion, 3 patients with wound infection and dehiscence were treated with two-stage debridement and suturing; the other patients achieved good healing with one-stage treatment. In addition, 1 case developed anal stenosis, which was corrected by a two-stage local flap-plasty. Three patients experienced local tissue overstaffing, and this outcome did not affect the functions of urination and defecation; similarly, there was no pain and discomfort. The remaining patients were basically satisfied with the local appearance, local scars were not obvious, and there was an absence of vaginal orificial, urethral orificial, or anal stenosis. Squamous cell carcinoma was the most commonly diagnosed cancer (80.8\%). In 7 patients (26.9\%), procedures were performed to treat recurrent cancer. The overall survival rate was $76.9 \%$. Rhomboid flaps were the most commonly used flaps for performing reconstruction in both the primary and recurrent groups.

\section{Discussion}

Vulvar carcinoma is a rare gynecologic cancer that affects approximately $5 \%$ of women. The most common histotype is squamous cell carcinoma, which is mainly caused by human papillomavirus in a majority of cases [8]. Other histological types of tumors involving the vulvar region include melanoma, basal cell carcinoma, sarcoma, adenocarcinoma, and verrucous carcinoma [9]. Staging of vulvar cancer was determined using the American Joint Committee on Cancer (TNM) and the International Federation of Gynecology and Obstetrics staging systems [10].

Surgery is the main treatment for vulvar cancer. Surgical treatment of malignant vulvar disease often requires resection of a large area of skin, and patients may experience significant morbidity if this area of skin is not replaced [11]. Vulvar reconstruction is critical for cosmetic, functional, and psychological reasons. Reconstruction of oncologic vulvar defects after ablation may be challenging because of scarcity of local tissue; and it should not impair important functions, including micturition, reproduction, and defecation [12].

Flap-based reconstruction is recommended for treating vulvar cancer regardless of whether it is primary or recurrent and early or late large lesions. Enlarged resection for vulvar cancer results in skin and soft tissue defects of different sizes; although the majority of small lesions can be sutured directly, there is a certain amount of wound tension and excessive tension 1) delays wound healing, 2) causes cracking, and 3) may even affect the blood supply to the skin (i.e., combined with the fact that the area is not clean). All these factors affect wound healing. For mid-advanced lesions, the defect is larger, the wound cannot be directly sutured and closed, and it is not easy to fix the skin graft (also: graft survival is difficult), and some wounds exposing large blood vessels or pubic bone require flap-based reconstruction. The wound healing ability after flap-based reconstruction is more advantageous than that after 
direct suturing or skin grafting; our approach is conducive to systemic chemotherapy, targeted therapy, and radiotherapy as soon as possible after surgery (thereby reducing the chances of local tumor recurrence and distant metastasis).

Reconstructive options include skin grafts, skin flaps, fasciocutaneous flaps, and myocutaneous flaps [13]. Flap choice is mainly determined by the size and location of the defect (unilateral, bilateral, close to the pubic symphysis or anus, and groin metastasis), whether there is the presence of recurrent lesions and local lymph node dissection, and/or a history of local radiotherapy pre-surgery. These factors influence the choice of flap. The vulva, perineum, mons pubis, groins, vagina, and urethra are the most frequently included structures in ablative surgery for vulvar cancer, and the rectum, bladder, and lower abdominal wall are the more rarely included structures. The vulvoperineal area is not the only included region in ablative surgery for vulvar cancer but close structures are also very frequently involved and a particular configuration of the defect is created by the combination of involved anatomical subunits (which limits the indications of various flaps every time).

With respect to the repair method of the defect, we follow the principle of "local flap $\rightarrow$ pedicled flap $\rightarrow$ free flap." Usually, skin grafting is not suitable due to the nature of the area and interference with its function and cosmesis. Flaps are invariably the best option for performing vulvoperineal reconstruction, and we propose using skin grafts only for skinning vulvectomy in Paget disease (where there is a thin defect and a high rate of relapse). Free flaps have been widely used for vulvoperineal reconstruction [4,14,15], but they are not considered the first treatment choice because of their complex management [16]. Although these flaps, in combination, cover most dimensions of defects resulting from resection for vulvar cancer, there are still some drawbacks, such as a difficult operation method, great damage to the donor area, and high technical requirements for the surgeon [17-19]. For small- and mediumsized defects after resection for vulvar cancer, a local flap should be used for repair. The local flap has the following characteristics: a simple operation, low trauma, short operation time, and similarity in the thickness and texture of the flap with the defect area (which can produce a good postoperative appearance). Surgeons can choose the local flap according to the size and location of the defect; these flaps include rhomboid flaps, modified rhomboid flaps, rotation flaps, and V-Y advanced flaps. For repair of small unilateral lesions, the flap from the labia minora can also be used. For treating a major defect of the labia majora, it is our recommendation to repair the vulva and thigh root with a V-Y advancement flap or advanced flap. For repair of a main defect of the pudendal area, we recommended using the rhomboid flap or advanced flap. For the repair of large metastatic lesions in the groin area, a local rhomboid flap (O-Z flap) can be used.

If the defect is large and affected by local lymphadenectomy (and there is a history of previous surgical incision or local radiotherapy), it is difficult to repair recurrent lesions with local flaps, and pedicled flaps can be considered. If necessary, kiss-flap technology or a combination of multiple flaps can be used to repair the defect and perform vulvoplasty. Studies have shown that the incidences of poor wound healing requiring debridement for perforator flaps and myocutaneous flaps are $22.4 \%$ and $25 \%$, respectively [20]. Compared to myocutaneous flaps, thinner perforator flaps are a better choice for treating some of the defects. According to the location and size of the defect, an iliac inguinal flap with superficial circumflex iliac artery, a medial femoral flap, an anterolateral femoral perforator flap, a VRAM flap, or a deep inferior epigastric artery perforator (DIEP) flap can be selected. Because there are many usable pedicled flaps around the vulva, the requirement and cost-effectiveness of free flaps are not high.

In many patients with early-stage vulvar cancer, the external urethral opening and perianal skin are not invaded; thus, the external urethral opening and anus need not be repaired. However, in middle- and late-stage lesions, tumor invasion is relatively large and the lesions are relatively close to the urethral opening or the perianal skin; they can even violate and disrupt the urethral opening and the perianal skin. In such a case, urethroplasty or anoplasty is often required. All relevant preoperative imaging examinations should be performed before surgery, especially PET-CT, to exclude distant metastasis and surgical contraindications. The MDT team, which is comprised of experts in the treatment department, including nutrition, imaging, pathology, blood transfusion, oncology, radiotherapy, biological, urology, anorectal surgery, ostomy, gynecologic oncology, plastic repair surgery, and other professionals (i.e., who conducted a full preoperative evaluation and discussion) should be consulted. Surgery is not recommended if the tumor cannot be completely removed due to locally advanced tumor invasion, the patient cannot withstand or is not willing to undergo major surgery, or the patient has a poor quality of life and poor prognosis postoperatively. It is necessary to formulate a comprehensive treatment and surgical plan in patients who have surgical indications. Longterm urethral stenosis or anal stenosis may occur because the epithelium around the urethral opening and the anus is brittle, the location is concealed, suturing is difficult, and there is a risk of delayed wound healing and splitting at the junction of the urethral opening or the anal preflap. In such a case, it is recommended to create a bladder fistula and perform colostomy simultaneously for tumor resection and repair; in cases in which the tumor is large and ruptures before surgery (and affects the urination and defecation of patients), creating a bladder fistula and performing colostomy can improve the local conditions and preoperative quality of life in patients. Because the vulvar area is contaminated, preventive bladder fistula and colostomy are performed in the above cases. After the operation, an ostomy specialist is invited to care for the wound and fistula, which can be conducive to postoperative wound care and can reduce wound infection. Early reduction of the occurrence of splitting and promoting wound healing is beneficial for comprehensive treatment, such as radiotherapy, chemotherapy, and targeted therapy (which can be performed early after surgery). The main limitations of this study are a small number of cases, the exclusive use of observational methods, inadequate follow-up time, and lack of a comparative control group.

\section{Conclusion}

Expanding resection is an effective technique for treating vulvar cancer, and postoperative surveillance is recommended to monitor for recurrence. Different skin flaps are effective premium options for postsurgical defect reconstruction, and selective use of skin flaps for treating vulvar defects preserves vulvar morphology and allows for relatively better functionality.

\section{Declarations}


The study followed the guidance of the ethics committee of Sun Yat-sen University, and all participants provided written informed consent.

\section{Consent for publication}

All presentations of case reports were consent for publication.

\section{Availability of data and materials}

The datasets used and/or analysed during the current study are available from the corresponding author on reasonable request.

\section{Competing interests}

The authors declare that they have no competing interests.

\section{Funding}

This study was supported by the 5010 Research Project of Sun Yat-sen University (2019017).

\section{Authors' contributions}

Jiaqi Zhang wrote the main manuscript text and Jian Zhang prepared figures. All authors reviewed the manuscript.

\section{Acknowledgements:}

This thesis would not have been possible without the consistent and valuable reference materials that I received from Pro. Weiqiang Liang, whose insightful guidance and enthusiastic encouragement in the course of my shaping this thesis definitely gain my deepest gratitude.

\section{References}

1. Fin A, Cordaro ER, Guarneri GF, et al. Experience with gluteal V-Y fasciocutaneous advancement flaps in vulvar reconstruction after oncological resection and a modification to the marking: Playing with tension lines [J]. Int Wound J. 2018;1-7

2. Stephanie T, Jennifer W, Marine B .Outcomes of the use of different vulvar flaps for reconstruction during surgery for vulvar cancer. European Journal of Surgical Oncology. 45 (2019) 1625-1631.

3. Hollenbeck ST, Toranto JD, Taylor BJ, Ho TQ, Zenn MR, Erdmann D, et al. Perineal and lower extremity reconstruction. Plast Reconstr Surg 2011;128:55163.

4. Salgarello M, Farallo E, Barone-Adesi L, Cervelli D, Scambia G, Salerno G, et al. Flap algorithm in vulvar reconstruction after radical, extensive vulvectomy. Ann Plast Surg 2005;54:184-90.

5. John HE, Jessop ZM, Di Candia M, Simcock J, Durrani AJ, Malata CM. An algorithmic approach to perineal reconstruction after cancer resection-experience from two international centers. Ann Plast Surg 2013;71:96-102.

6. Friedman J, Dinh T, Potochny J. Reconstruction of the perineum. Semin Surg Oncol 2000;19:282-93.

7. Saleh DB, Liddington MI, Loughenbury P, Fenn CW, Baker R, Burke D. Reconstruction of the irradiated perineum following extended abdomino-perineal excision for cancer: an algorithmic approach. J PlastReconstr Aesthet Surg 2012;65:1537-43.

8. Fin A, Cordaro ER, Guarneri GF, et al. Experience with gluteal V-Y fasciocutaneous advancement flaps in vulvar reconstruction after oncological resection and a modification to the marking: Playing with tension lines. Int Wound J. 2018;1-7.

9. Koh WJ, Greer BE, Abu-Rustum NR, et al. Vulvar cancer, version 1.2017,NCCN clinical practice guidelines in oncology. J Nat/ Compr Canc Netw.2017;15(1):92-120.)

10. Pecorelli S. Revised FIGO staging for carcinoma of the vulva, cervix, and endometrium. Int J Gynaecol Obstet 2009;105(2):103-4. ).

11. Weikel W, Schmidt M, Steiner E, Knapstein PG, Koelbl H (2008) Reconstructive plastic surgery in the treatment of vulvar carcinomas. Eur J Obstet Gynecol Reprod Biol 136(1):102-109)

12. Al-Benna S, Tzakas E (2012) Postablative reconstruction of vulvar defects with local fasciocutaneous flaps and superficial fascial system repair. Arch Gynecol Obstet 286(2):443-448. doi:10.1007/s00404-012-2262-1)

13. Wills A, Obermair A.A review of complications associated with the surgical treatment of vulvar cancer . J Gynecol Oncol. 2013;131: 467-479)

14. John HE, Jessop ZM, Di Candia M, Simcock J, Durrani AJ, Malata CM. An algorithmic approach to perineal reconstruction after cancer resectionexperience from two international centers. Ann Plast Surg 2013;71:96-102.

15. Negosanti L, Sgarzani R, Fabbri E, Palo S, Oranges CM, De laco P, et al. Vulvar reconstruction by perforator flaps: algorithm for flap choice based on the topography of the defect. Int J Gynecol Cancer 2015;25:1322-7. 
16. Lazzaro L, Guarneri GF, Rampino Cordaro E, Bassini D, Revesz S, Borgna G, Parodi PC (2010) Vulvar reconstruction using a "V-Y" fascio-cutaneous gluteal flap: a valid reconstructive alternative in post-oncological loss of substance. Arch Gynecol Obstet 282(5):521-527. doi:10.1007/s00404-010-16031

17. John HE, Jessop ZM, Di Candia M, Simcock J, Durrani AJ, Malata CM. An algorithmic approach to perineal reconstruction after cancer resectionexperience from two international centers. Ann Plast Surg 2013;71:96-102.

18. Friedman J, Dinh T, Potochny J. Reconstruction of the perineum. Semin Surg Oncol 2000;19:282-93.

19. Saleh DB, Liddington MI, Loughenbury P, Fenn CW, Baker R, Burke D. Reconstruction of the irradiated perineum following extended abdomino-perineal excision for cancer: an algorithmic approach. J Plast Reconstr Aesthet Surg 2012;65:1537-43.

20. Elia J『Do NTK『Chang TNJ『et al.Redefifining the Reconstructive Ladder in Vulvoperineal Reconstruction: The Role of Pedicled Perforator Flaps[J]. J Reconstr Microsurg 2021;1-17.

\section{Tables}

Table 1

\begin{tabular}{ll}
\hline \multicolumn{2}{c}{ Clinical data } \\
\hline Age,years,mean(range) & $54.5 \pm 12.7(28-73)$ \\
Mean interval of desease before surgery & $4.2 \pm 1.9(2-9)$ \\
Ylinical stage, number(ra) & $2(7.7 \%)$ \\
I & $10(38.5 \%)$ \\
II & $10(38.5 \%)$ \\
III & $4(15.4 \%)$ \\
Site,number(\%) & \\
Perineum without & $16(61.5 \%)$ \\
Vagina/urethra/anus & $5(19.2 \%)$ \\
Perineum with anus & $8(30.8 \%)$ \\
Perineum with vagina & $2(7.7 \%)$ \\
Perineum with urethra & $10(38.5 \%)$ \\
Perineum and pubic mound & $13(50 \%)$ \\
Surgical techniques, number(\%) & $4(15.4 \%)$ \\
Rhomboid flap & $6(23.1 \%)$ \\
V-Y flap & $1(3.9 \%)$ \\
Medial femoral flap & $2(7.7 \%)$ \\
VRAM flap & $35.2 \pm 11.5(15-50)$ \\
Combined flap & \\
Follow up, months,mean(range) &
\end{tabular}

Table 2

\section{Figures}




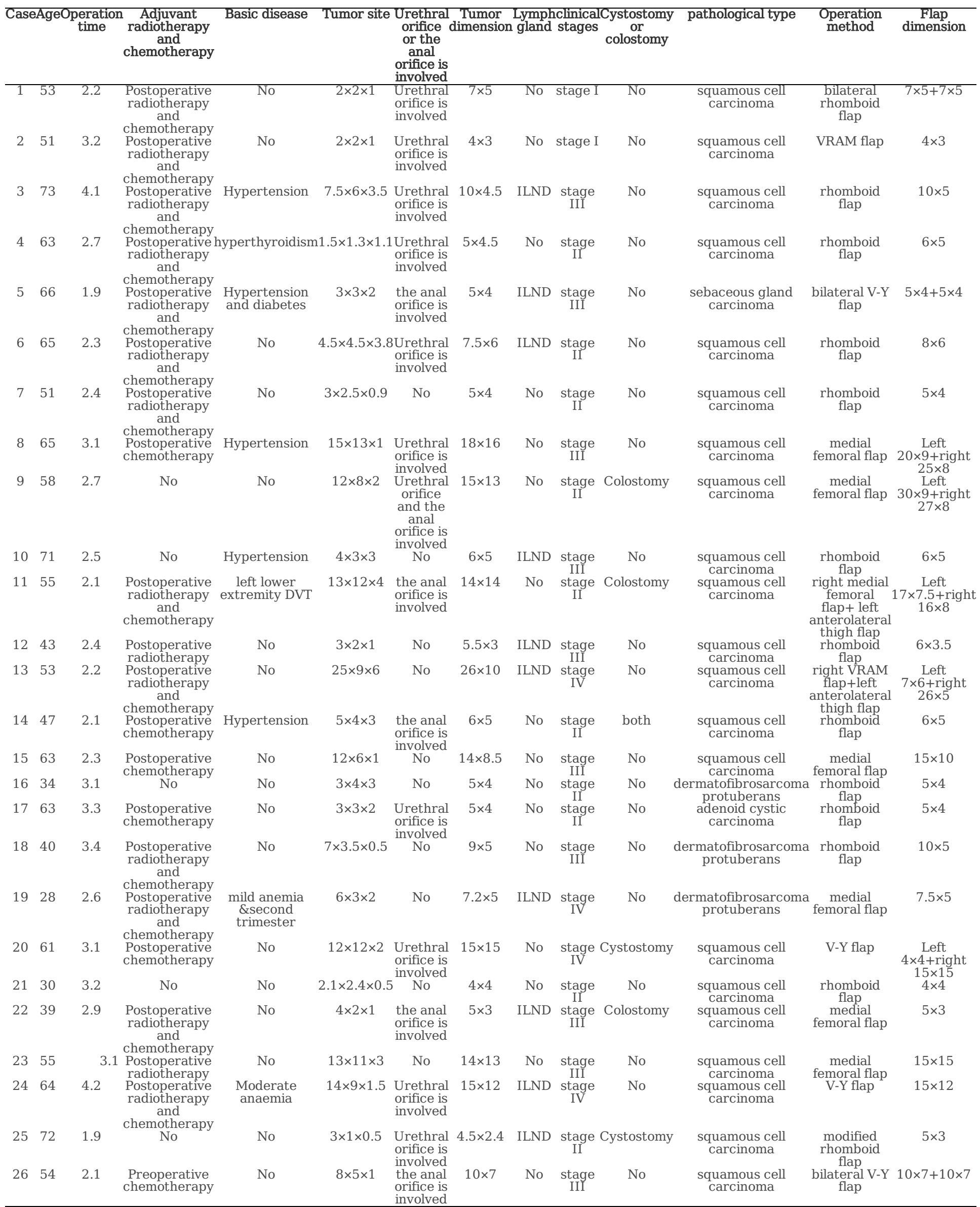




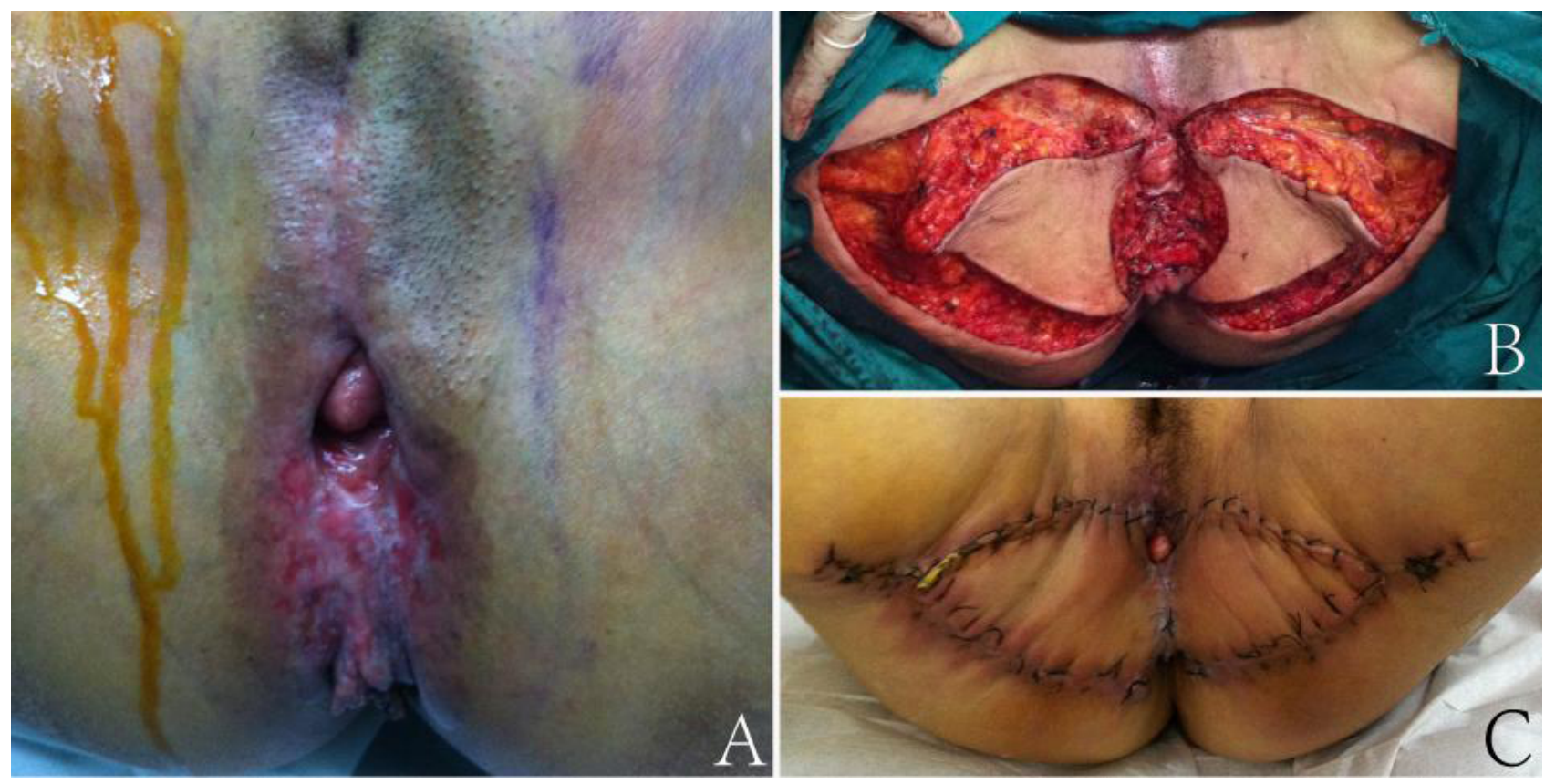

\section{Figure 1}

(A) Female, $66 \mathrm{Y}$. The size of the wound after vulvar sebaceous gland carcinoma expansion is $5 \mathrm{~cm} \times 4 \mathrm{~cm}$. (B) Design of a bilateral V-Y flap, $5 \mathrm{~cm} \times 4 \mathrm{~cm}$ $+5 \mathrm{~cm} \times 4 \mathrm{~cm}$. (C) The flap completely covers the wound.

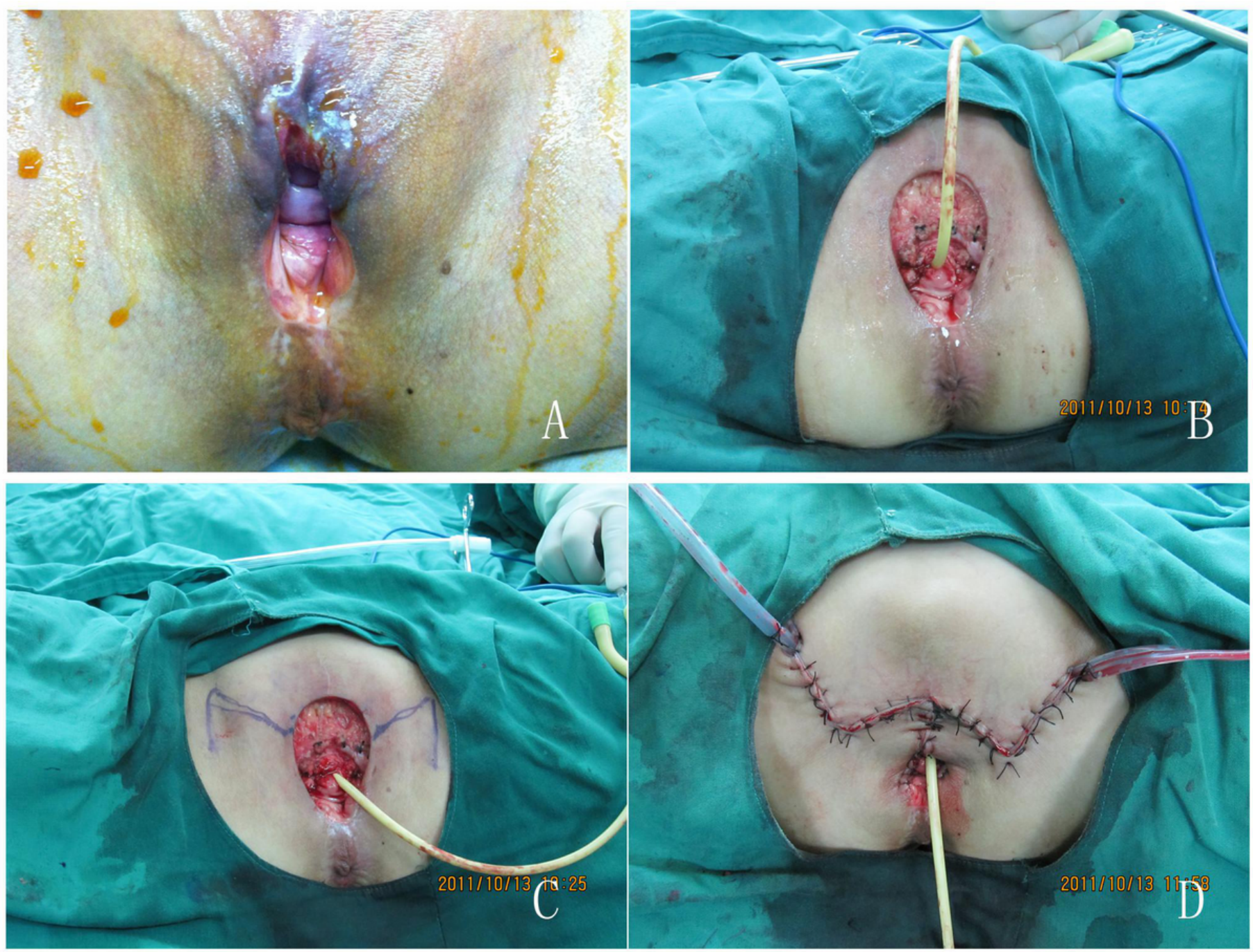


(A) (B) Female, 53 Y. The size of the wound after vulvar squamous cell carcinoma expansion is $7 \mathrm{~cm} \times 5 \mathrm{~cm}$. (C) Design of a bilateral rhomboid flap, $7 \mathrm{~cm}$ $\times 5 \mathrm{~cm}+7 \mathrm{~cm} \times 5 \mathrm{~cm}$. (D) The flap completely covers the wound.

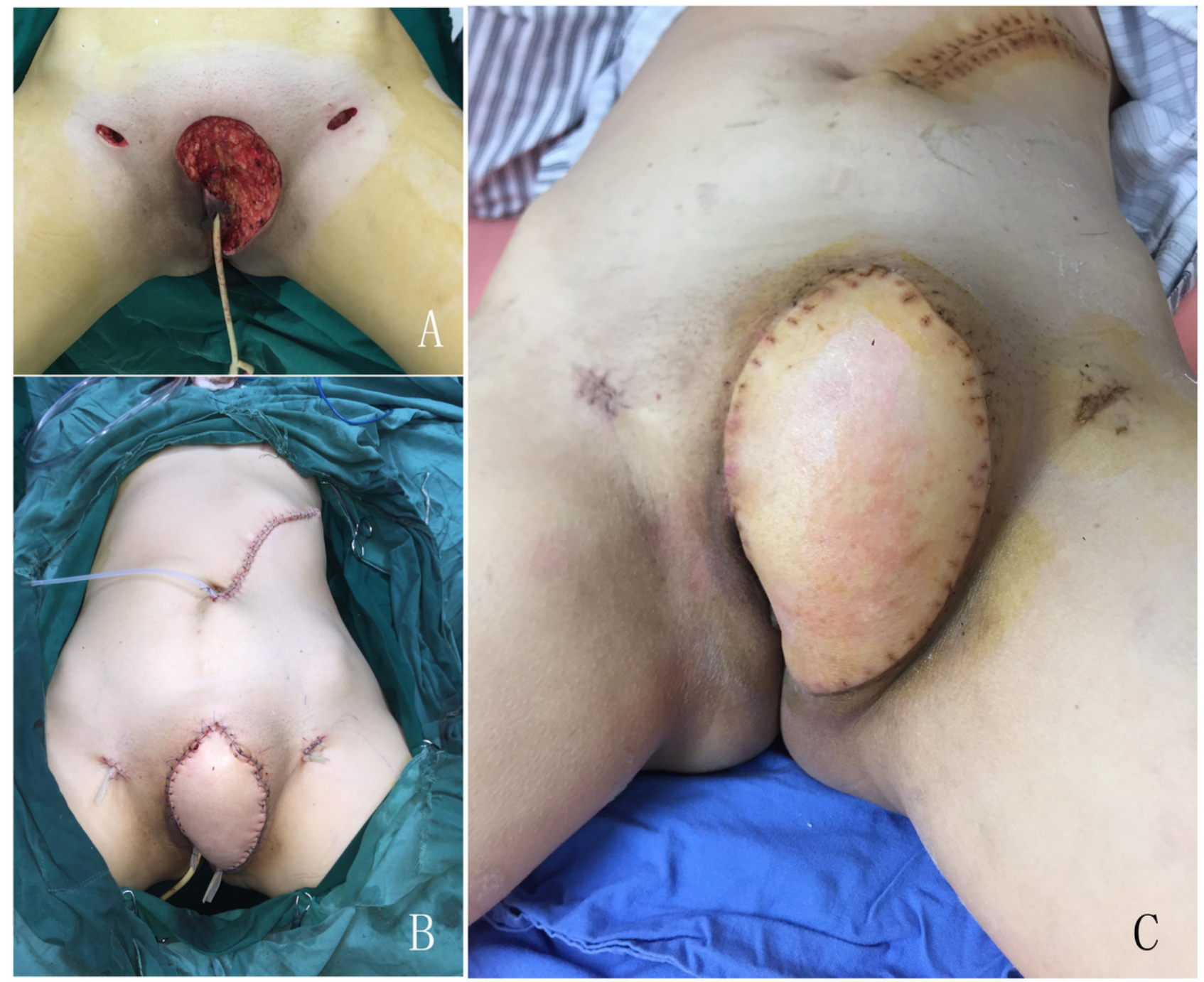

\section{Figure 3}

(A) Female, 51 Y. The size of the wound after vulvar squamous cell carcinoma expansion is $4 \mathrm{~cm} \times 3 \mathrm{~cm}$. (B) Design of a VRAM flap, $4 \mathrm{~cm} \times 3 \mathrm{~cm}$. The flap completely covers the wound. (C) Two weeks after surgery. 

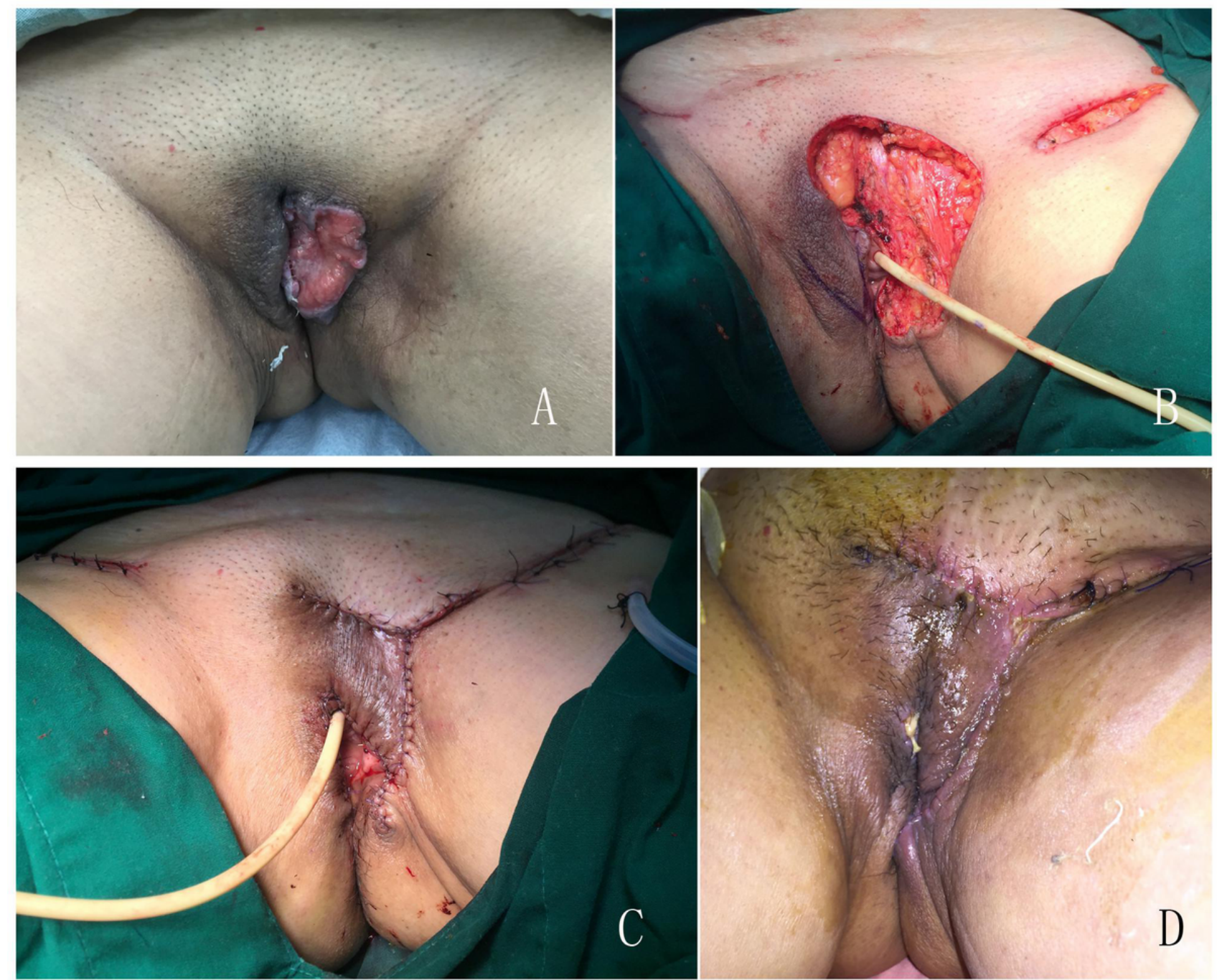

Figure 4

(A) Female, $71 \mathrm{Y}$. The size of the wound after vulvar squamous cell carcinoma expansion is $6 \mathrm{~cm} \times 5 \mathrm{~cm}$. (B) Design of a rhomboid flap, $6 \mathrm{~cm} \times 5 \mathrm{~cm}$. (C) The flap completely covers the wound. (D) Two weeks after surgery.
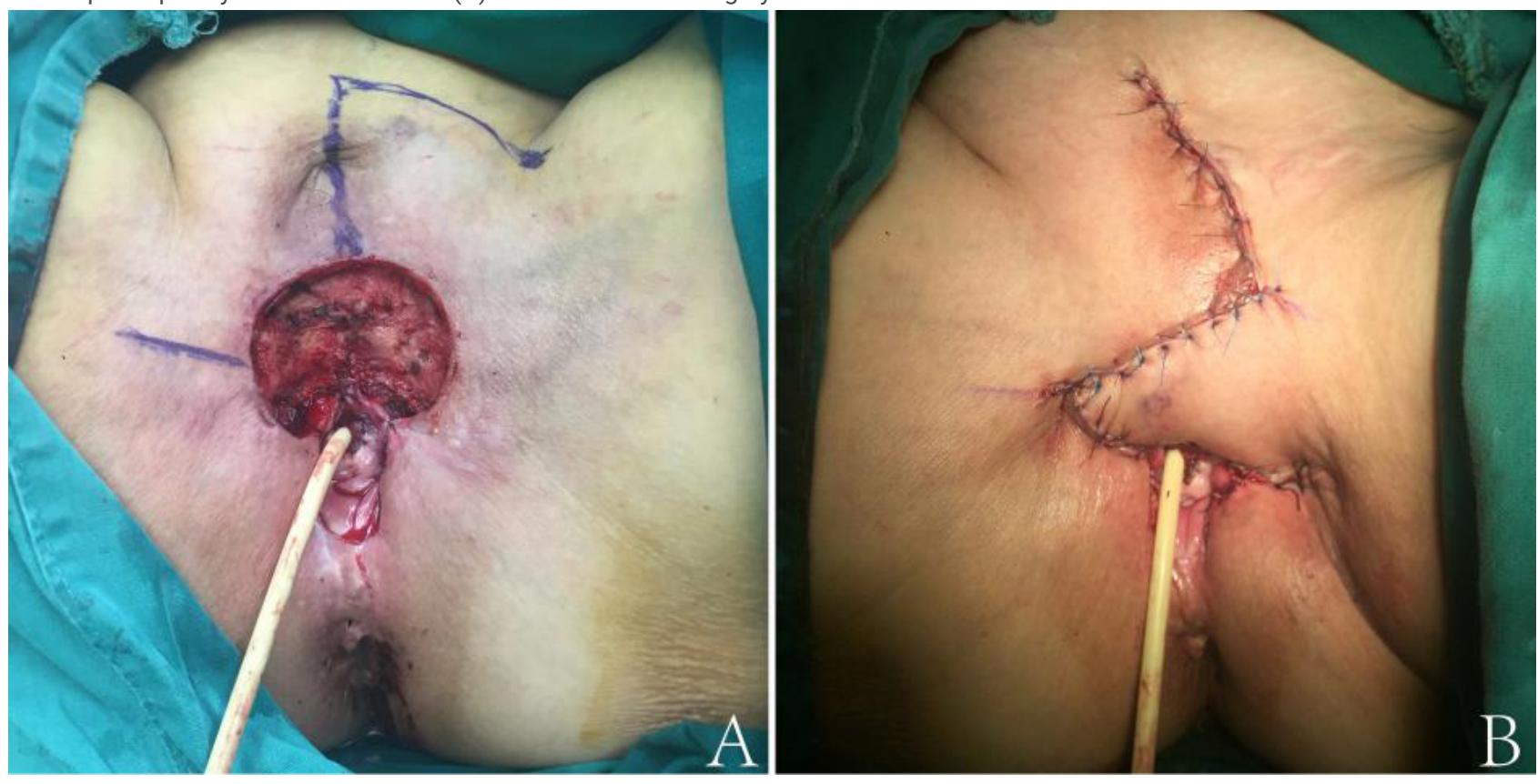

Figure 5 
(A) Female, 73 Y. The size of the wound after vulvar squamous cell carcinoma expansion is $5 \mathrm{~cm} \times 4.5 \mathrm{~cm}$. Design of a rhomboid flap, $6 \mathrm{~cm} \times 5 \mathrm{~cm}$. (B) The flap completely covers the wound.

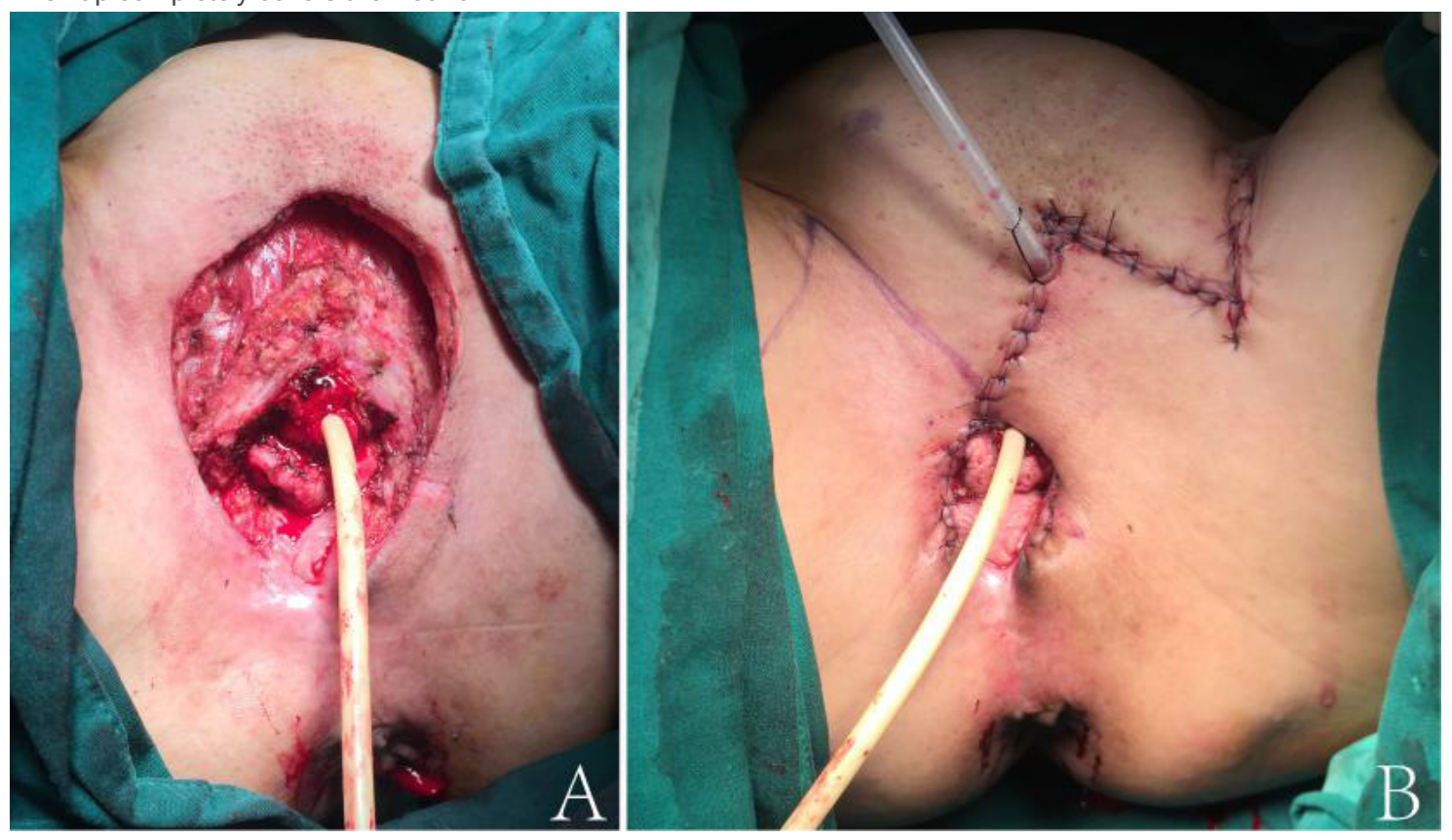

\section{Figure 6}

(A) Female, 65 Y. The size of the wound after vulvar squamous cell carcinoma expansion is $7.5 \mathrm{~cm} \times 6 \mathrm{~cm}$. Design of a rhomboid flap, $8 \mathrm{~cm} \times 6 \mathrm{~cm}$. (B) The flap completely covers the wound.

\section{Figure 7}

(A) Female, $65 \mathrm{Y}$. The size of the wound after vulvar squamous cell carcinoma expansion is $18 \mathrm{~cm} \times 16 \mathrm{~cm}$. (B) (C) Design of a medial femoral flap, left 20 $\mathrm{cm} \times 9 \mathrm{~cm}+$ right $25 \mathrm{~cm} \times 8 \mathrm{~cm}$. (D) (E) The flap completely covers the wound. 


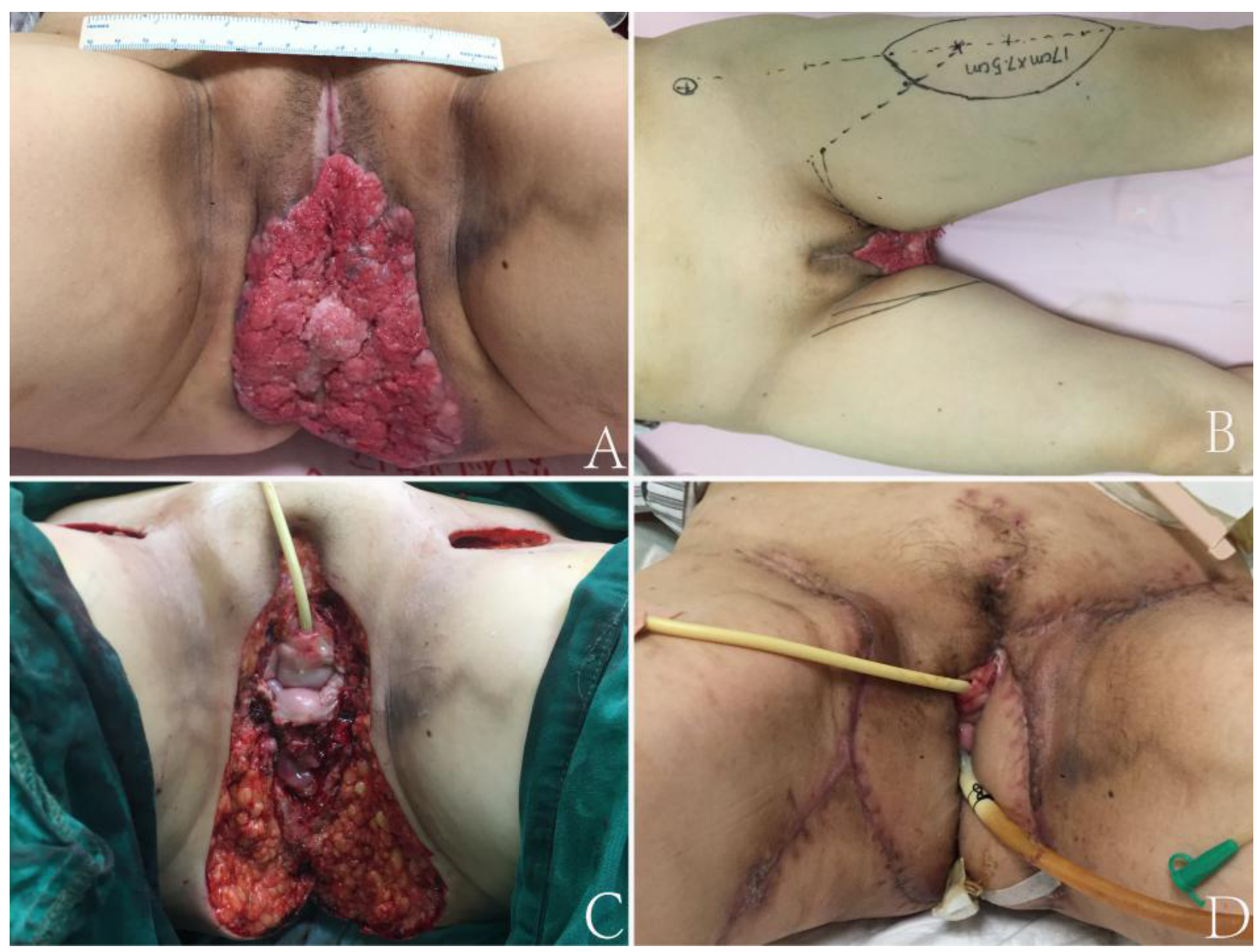

\section{Figure 8}

(A) (C) Female, $55 \mathrm{Y}$. The size of the wound after vulvar squamous cell carcinoma expansion is $14 \mathrm{~cm} \times 14 \mathrm{~cm}$. (B) Design of a right medial femoral flap 16 $\mathrm{cm} \times 8 \mathrm{~cm}+$ left anterolateral thigh flap $17 \mathrm{~cm} \times 7.5 \mathrm{~cm}$. The flap completely covers the wound. (D) Two weeks after surgery. 

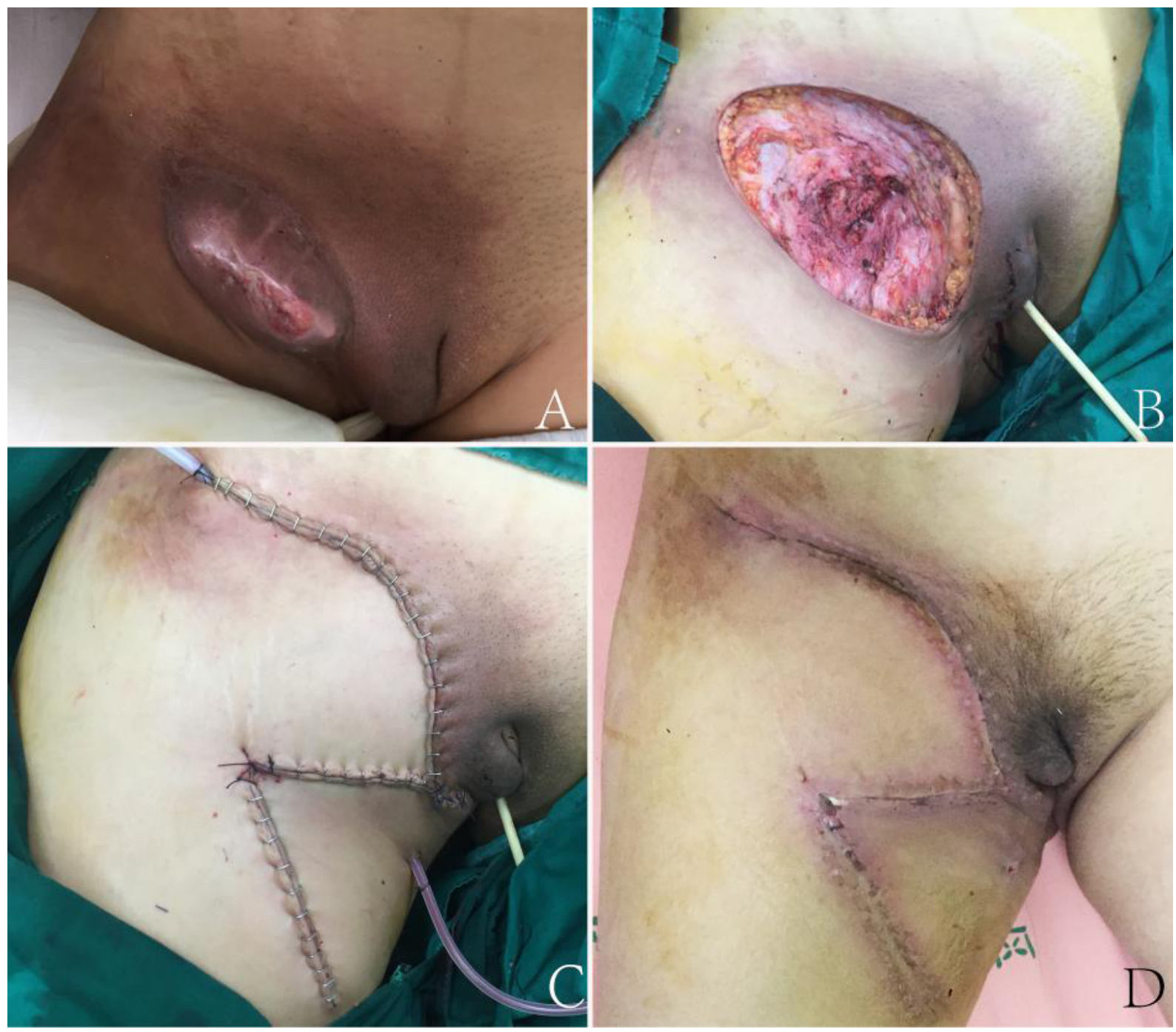

Figure 9

(A) Female, 73 Y. The size of the wound after vulvar squamous cell carcinoma expansion is $13 \mathrm{~cm} \times 8 \mathrm{~cm}$. (B) Design of a rhomboid flap, $13 \mathrm{~cm} \times 8 \mathrm{~cm}$. (C) The flap completely covers the wound. (D) Two weeks after surgery. 

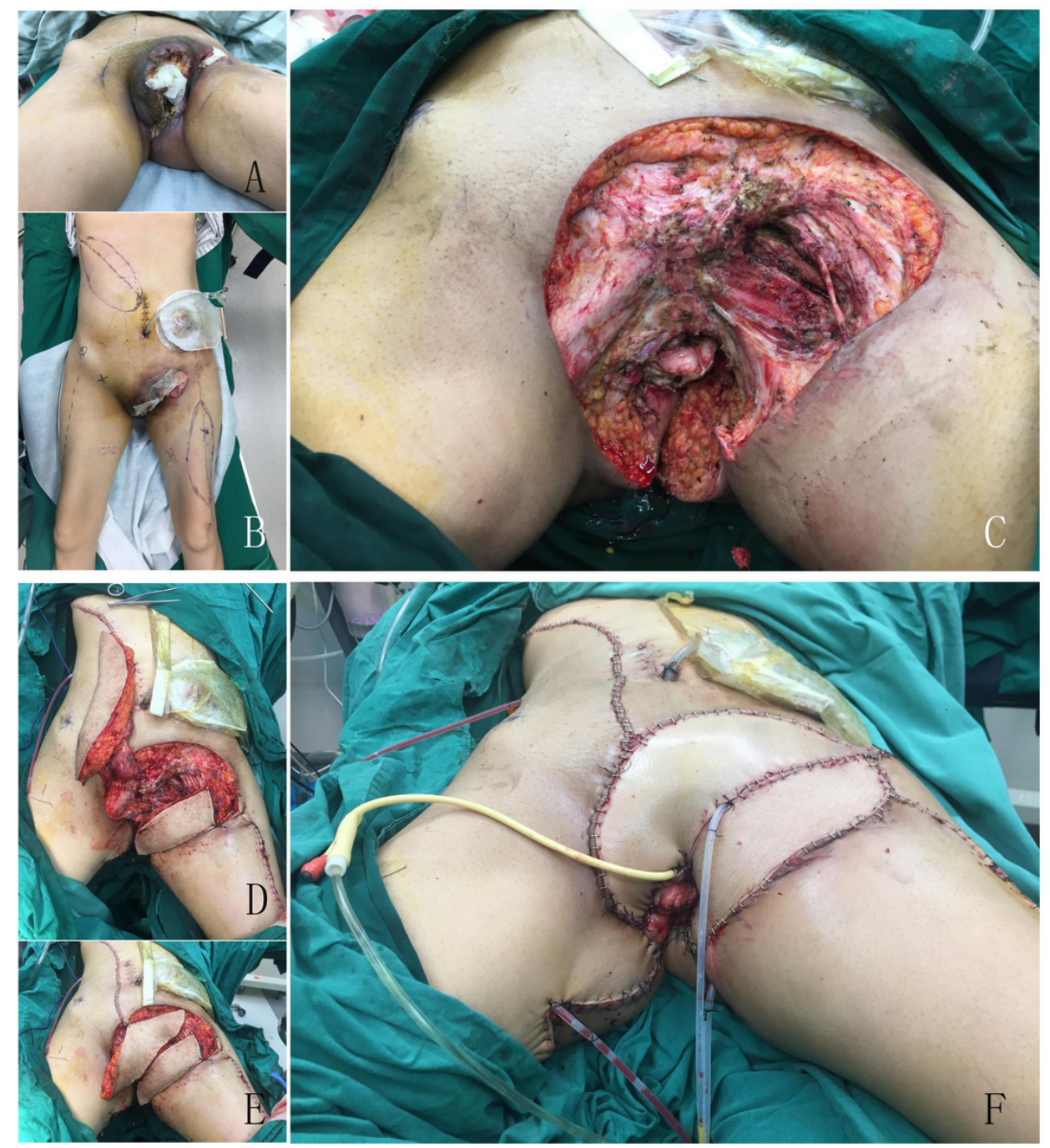

\section{Figure 10}

(A) (C) Female, 53 Y. The size of the wound after vulvar squamous cell carcinoma expansion is $26 \mathrm{~cm} \times 10 \mathrm{~cm}$. (B) (D) (E) Design of the right VRAM flap 26 $\mathrm{cm} \times 5 \mathrm{~cm}+$ left anterolateral thigh flap $7 \mathrm{~cm} \times 6 \mathrm{~cm}$. (F) The flap completely covers the wound.

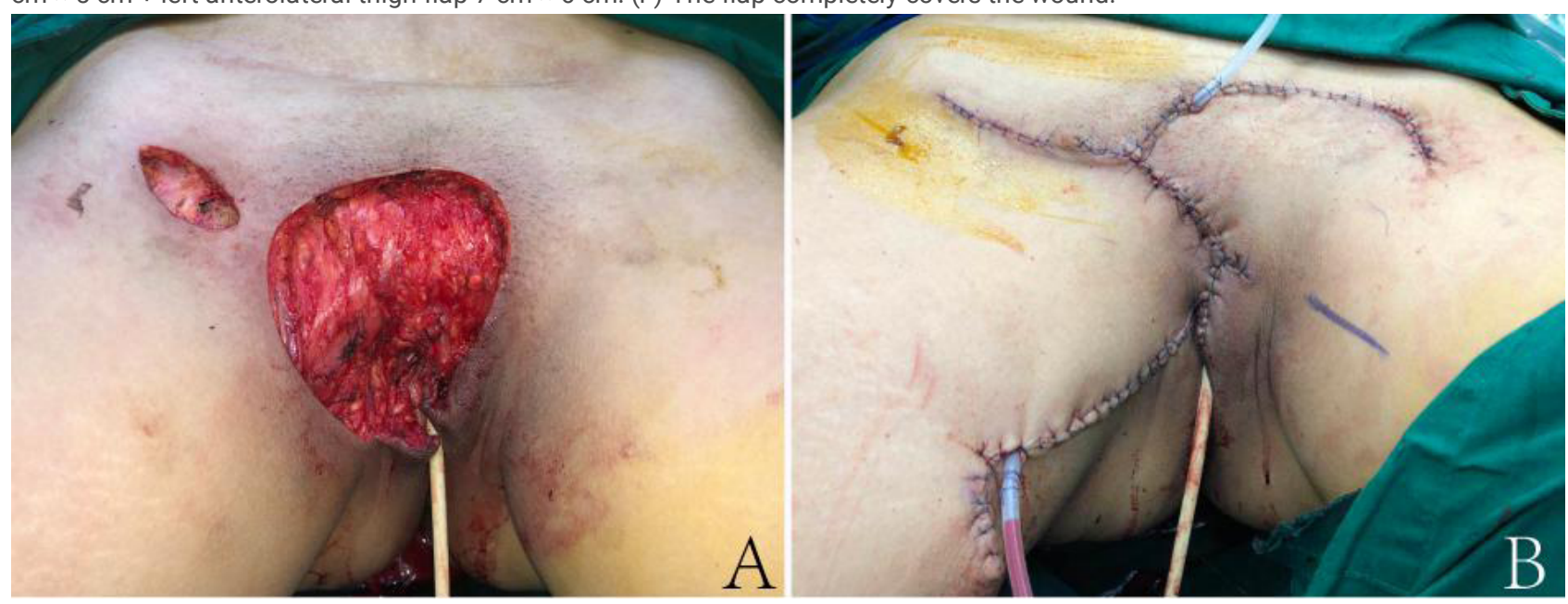

\section{Figure 11}

(A) Female, 40 Y. The size of the wound after dermatofibrosarcoma protuberans expansion is $9 \mathrm{~cm} \times 5 \mathrm{~cm}$. Design of a rhomboid flap, $10 \mathrm{~cm} \times 5 \mathrm{~cm}$. (B) The flap completely covers the wound. 

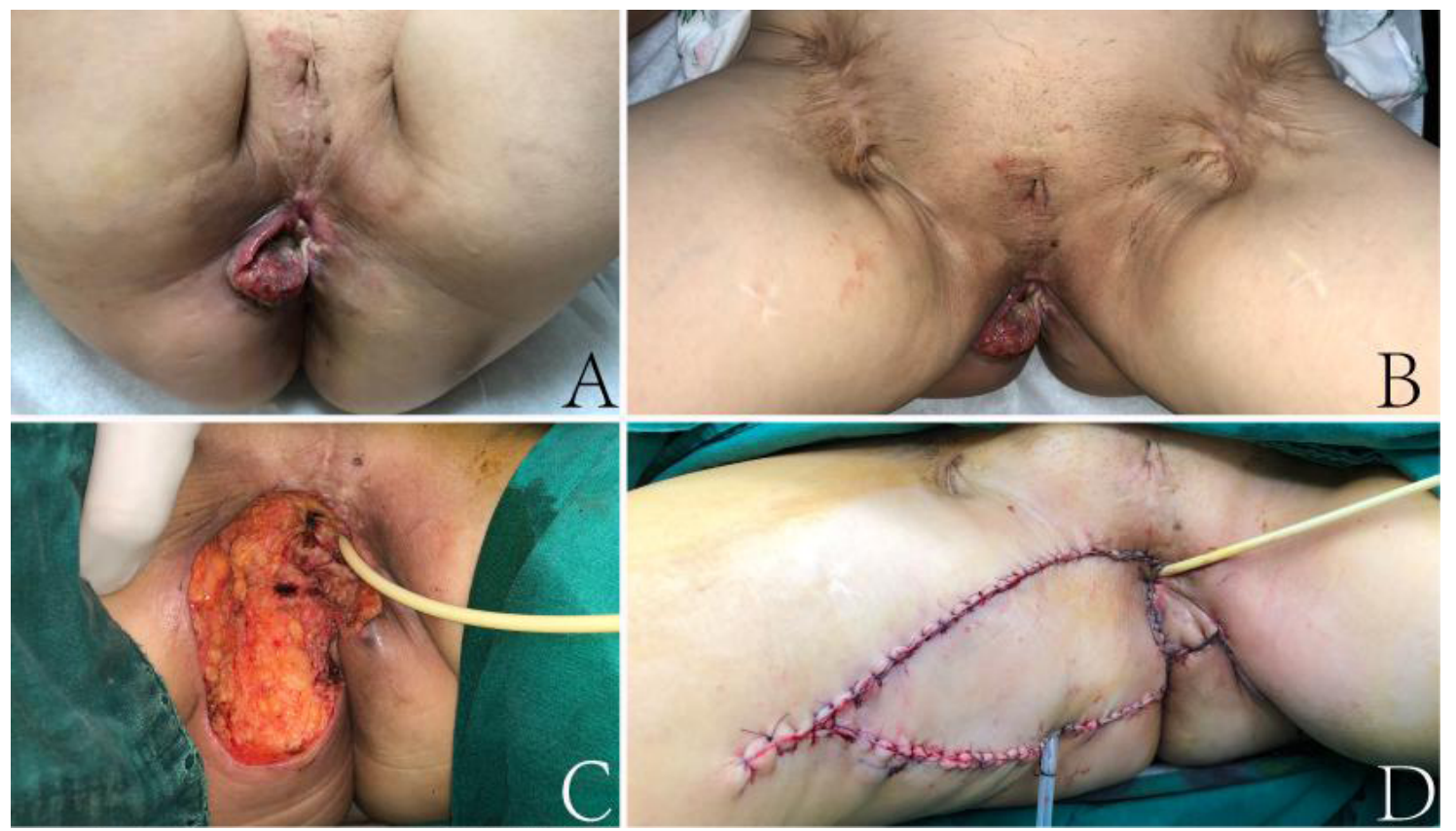

Figure 12

(A) (B) Female, $61 \mathrm{Y}$. The size of the wound after vulvar squamous cell carcinoma expansion is $15 \mathrm{~cm} \times 15 \mathrm{~cm}$. (C) Design of a V-Y flap, right $15 \mathrm{~cm} \times 15$ $\mathrm{cm}+$ left $4 \mathrm{~cm} \times 4 \mathrm{~cm}$. (D) The flap completely covers the wound.

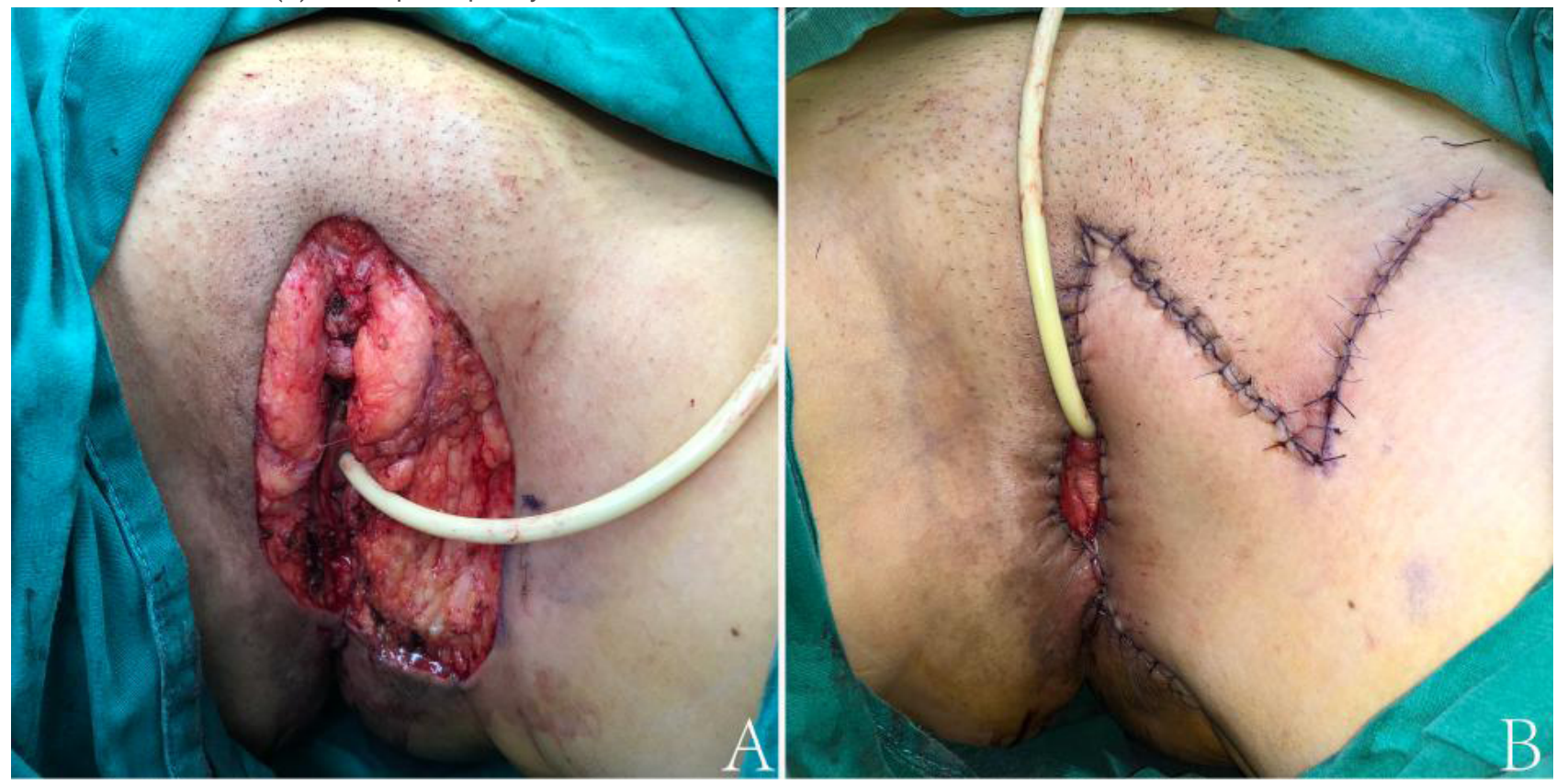

\section{Figure 13}

(A) Female, $62 \mathrm{Y}$. The size of the wound after Paget's disease expansion is $5 \mathrm{~cm} \times 4 \mathrm{~cm}$. Design of a rhomboid flap, $5 \mathrm{~cm} \times 4 \mathrm{~cm}$. (B) The flap completely covers the wound. 

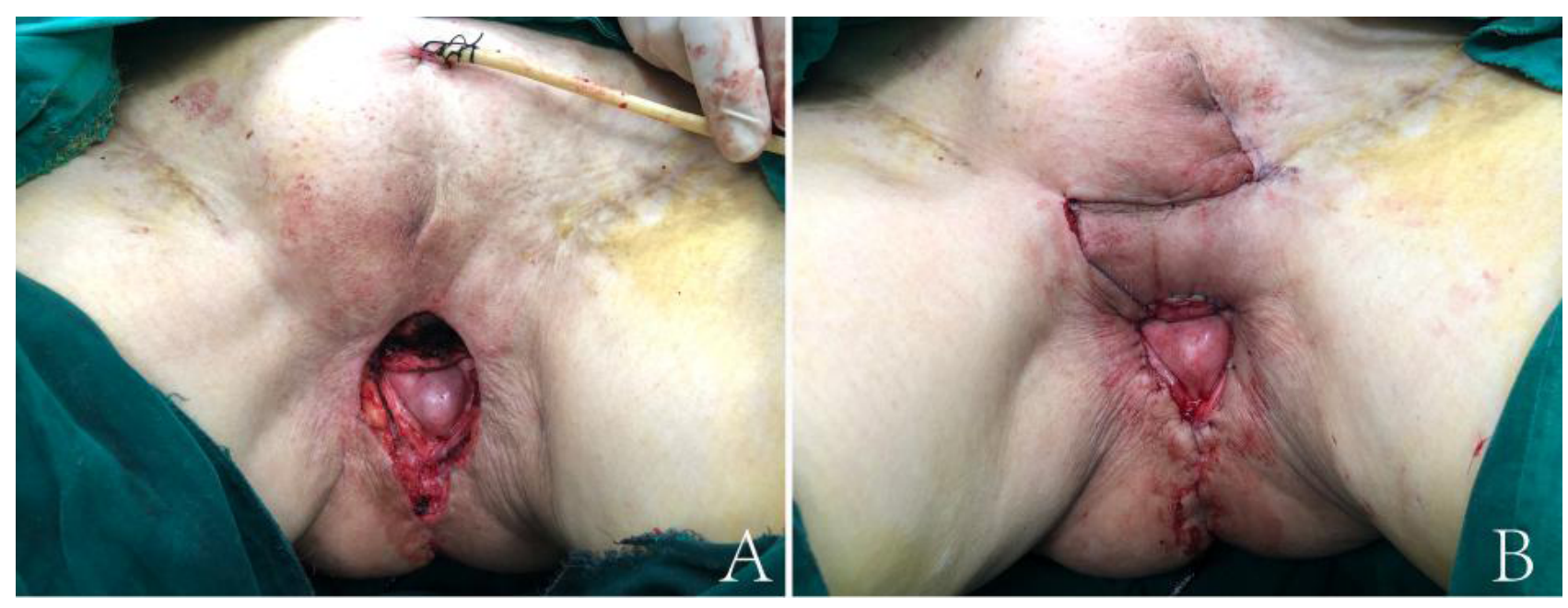

\section{Figure 14}

(A) Female, 72 Y. The size of the wound after vulvar squamous cell carcinoma expansion is $4.5 \mathrm{~cm} \times 2.4 \mathrm{~cm}$. Design of a rhomboid flap, $5 \mathrm{~cm} \times 3 \mathrm{~cm}$. (B) The flap completely covers the wound.
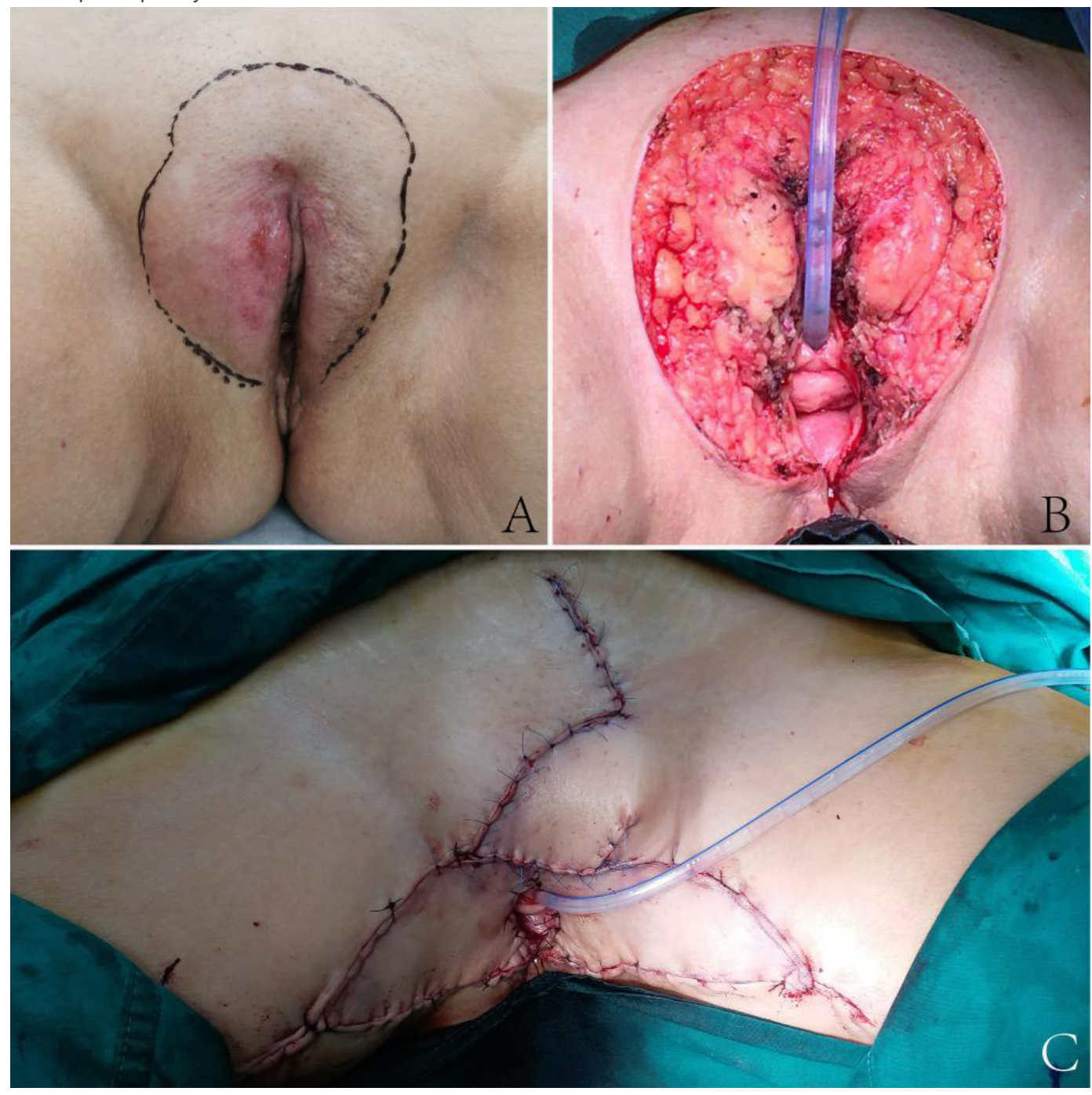

\section{Figure 15}

(A) Female, 73 Y. The size of the wound after Paget's disease expansion is $12 \mathrm{~cm} \times 10 \mathrm{~cm}$. (B) Design of a V-Y flap $9 \mathrm{~cm} \times 7 \mathrm{~cm}+$ modified rhomboid flap 5 $\mathrm{cm} \times 3 \mathrm{~cm}$. (C) The flap completely covers the wound. 
(A) Female, $54 \mathrm{Y}$. The size of the wound after vulvar squamous cell carcinoma expansion is $10 \mathrm{~cm} \times 7 \mathrm{~cm}$. (B) Design of a bilateral V-Y flap, $10 \mathrm{~cm} \times 7 \mathrm{~cm}$ $+10 \mathrm{~cm} \times 7 \mathrm{~cm}$. The flap completely covers the wound. (C) Two weeks after surgery. 